\title{
9 Gradation, aspect, and telicity
}

In the previous chapters, I presented three case studies on verbal degree gradation. In the first part of the current chapter, I want to broaden the general picture and to present a short discussion of further semantic classes of gradable verbs. This discussion will be concluded by a summary of the different subcompositional patterns. In the second section 9.2, the notion of 'subcompositionality' is discussed in detail and I demonstrate why verbal degree gradation is subcompositional. Finally, I will turn in 9.3 to a discussion of the interaction between degree gradation and grammatical aspect as well as telicity.

\subsection{Compositional patterns}

In chapters 6 to 8 , three different semantic verb classes were discussed with respect to verbal degree gradation. In section 9.1.1, I will summarize the different patterns of verb degree gradation found with the semantic verb classes discussed in the foregoing chapters. In the sections 9.1.2 to 9.1.4, I will broaden the view and shortly discuss more patterns of verbal degree gradation that can be found in German and other languages. The aim of section 9.1.5 is to illustrate similarities between the different compositional patterns.

\subsubsection{Changes, emissions, and experiences}

Change of state verbs express a scalar change in a property of the referent of their theme argument. Degree gradation applies to that scale and either specifies the degree of change, as in the case of degree achievements, or further specifies the degree of the attained result state, which is the case for accomplishments.

Verbs of emission can be classified into in four different subclasses, and three of them show similar patterns regarding verbal degree gradation. In 
the case of verbs of sound emission, light emission and smell emission, degree gradation affects an intensity scale. The scale represents a gradable property of the implicit emittee argument. Verbs of substance emission differ in that the scale does not measure intensity but quantity. The quantity scale represents a gradable property of the emitted substance as is the case for the scales of the other subtypes of verbs of emission.

Experiencer verbs form a rather heterogeneous verb class consisting of verbs showing different linking patterns as well as belonging to different aktionsart classes (in chapter 8, I showed that these differences go together with differences in the lexical semantics of the verbs). Despite the heterogeneity of experiencer verbs, verbal degree gradation is uniform in specifying a degree on an intensity scale. The scale represents a gradable property of the experiencer's attitude.

The different types of gradation scales found in these three semantic classes of verbs are summarized in table 16. Following Rappaport Hovav (2008) among others, I use the term 'property scale' as a general notion for the different scales lexicalized by change of state verbs. Examples of such property scales are 'size,' 'weight,' 'price,' 'temperature' and so on. Even if different verb classes are related to intensity scales, the exact interpretation of the notion of 'intensity' differs from verb class to verb class. Regarding sound emission, intensity can be understood as 'loudness,' whereas with respect to light emission, intensity is 'brightness.' Interestingly, English employs the synonyms 'sound intensity' and 'light intensity' for 'loudness' and 'lightness' respectively, whereas German does not. For smell emission and sensations 'intensity' is probably the best and only term that can be used. 'Quantity', in the case of verbs of substance emission, could also be conceived as 'volume'; it measures an amount of substance.

\begin{tabular}{|l|l|}
\hline Verb class & Type of scale \\
\hline Change of state verbs & Property scale \\
\hline Verbs of sound/smell/light emission & Intensity scale \\
\hline Verbs of substance emission & Quantity scale \\
\hline Experiencer verbs & Intensity scale \\
\hline
\end{tabular}

Table 16: Classes of verbs and their associated types of scales. 
In addition to the different scales, we also observe differences in the kind of verbal degree gradation. There is a difference between indicating a differential degree, as is the case for change of state verbs, and a non-differential one, as for verbs of emission and experiencer verbs. In the case of a differential degree, the intensifier specifies the difference between two degrees. For change of state verbs, this is a difference between an initial degree and a final degree at the end of a change of state event. Roughly speaking, a differential degree indicates a difference between two arbitrary degrees on a scale and the intensifier further specifies the extent of the difference between these degrees. The notion of a 'differential degree' is not restricted to scalar changes and I will present examples in the next subsection.

In the case of verbs of emission and experiencer verbs, the intensifier does not specify a difference between two degrees. If one takes frighten as an example, then it is not the case that the intensifier specifies the divergence between the initial degree of frightening and a final one. This does not mean that grading experiencer verbs, for example, can never lead to a specification of a difference degree. In fact, we have seen such cases, as provided by certain prefixed verbs in Russian and Polish. In chapter 8 , the Russian prefixed verb po-ljubit' meaning 'to fall in love' has been mentioned. Prefixation derives a perfective change of state predication of the imperfective state verb ljubit' 'love.' Although, in the latter case, degree gradation affects the intensity of love, in the former case it specifies the resulting change. But this is a derived interpretation; the change of state component is induced by the verbal prefix. I will turn to similar examples in section 9.1 .3 below.

\subsubsection{Verbs expressing divergence $\&$ similarity}

In his discussion of verb gradation, Löbner (2012b) mentions two classes of verbs which are of interest in the current section. He calls these classes 'verbs of comparison' and 'verbs of marked behavior.' What is interesting about these verbs is that they express a difference between degrees without denoting a change of state.

Starting with verbs of comparison: this class consists of verbs like sich ähneln 'be similar' and sich unterscheiden 'differ.' These verbs are quite general and express some similarity or difference regarding an unspecified property. In (1a), one has to infer the respective property with respect 
to which the two books are similar; this could be the content, the way the book looks or whatever other properties the books have. But, as also indicated in the example, the respective dimension of comparison can be made explicit. Verbs of comparison are similar to such change of state verbs like steigen 'rise' with respect to scalar underspecification (cf. the discussion in section 6.3). As (1b) shows, verbs of comparison can be graded and it is the degree of similarity that is specified by sehr.
a. Die beiden Bücher ähneln sich (im Aussehen). the both books be.similar REFL in.the appearance 'The two books are similar in appearance./The two books look similar.'
b. Die beiden Bücher ähneln sich sehr. the both books be.similar REFL very 'The two books are very similar.'

Regarding verbs of comparison, the intensifier specifies a difference value. For sich ähneln, it is expressed that the difference between the two degrees which are the degrees the compared objects have in the respective dimension is small. For a verb such as sich unterscheiden 'differ,' sehr indicates that this difference is very large. The attribute chain which links the scale of sich ähneln to the eventuality is shown in (2). As the representation indicates, SIMILARITY is a comparison between properties of the verb's syntactic arguments and it is not an attribute of an implicit argument of the verb. The scale is lexically encoded in the verb as sich ähneln always expresses a comparison and not just in the context of degree gradation. Hence, the scale is not retrieved from the conceptual knowledge.

(2) $\llbracket$ sich sehr ähneln $\rrbracket=\lambda \mathrm{x} \lambda \mathrm{y} \lambda \mathrm{v}$.(high(SIMILARITy(APPEARANCE $(\operatorname{THEME}(\mathrm{x}))$, APPEARANCE(COMPARANDum(y))(v))))

The same holds for the Russian example in (3). The verb otličat'sja 'differ' is derived from otličat' 'distinguish.' Only the base verb shows an aspectual opposition but not the derived stative predicate, which is imperfective. In (4), a French example is shown which indicates that beaucoup can also be used for grading verbs of comparison. 
Nov-aja glav-a očen'otličaet-sja ot star-oj glav-y. new-nom chapter-nom very differs-refl PREP old.ACC chapter-ACC 'The new chapter differs very much from the old one.'

(4) Elle se différencie beaucoup de sa sour. she REFL differs a lot of her sister 'She differs a lot from her sister.'

Verbs of comparison express a static predication since the values of two objects in a certain, maybe unspecified, dimension are compared. These verbs do not denote an increase or decrease in similarity, which shows that difference values are also found with stative verbs. This is also indicated by the paraphrase of example (1a) in (5).
Die beiden Bücher sind sich sehr ähnlich(im Aussehen). the both books are REFL very similar in.the appearance 'The two books are very similar in appearance.'

The German paraphrase, similar to the English translation of the example, makes use of an adjective. This is not surprising as many languages express comparative constructions by using verbs, as they lack a distinct category of adjectives (cf. Stassen 1984, 1985). In contrast to comparative constructions, verbs of comparison are less specific in German. Most adjectival comparatives in German express a comparison in a concrete dimension, as the adjective itself is related to such a dimension. Exceptions to this are the adjectives anders (als) 'different (to/than), verschieden (von) 'different from' and ähnlich $(z u)$ 'similar to' which are unspecific regarding the dimension.

The second class of verbs mentioned above - verbs of marked behavior - is represented by verbs like stottern 'stutter', lispeln 'lisp,' hinken 'limp' or schielen 'squint.' These verbs express that the referent of the subject argument diverges from some norm. In the case of stottern and lispeln, it is expressed that the way the subject referent is speaking diverges from the normal way of speaking. Both verbs denote different types of divergences from the normal manner of speaking.

In (6) it is shown that these verbs can be graded by sehr. Löbner (2012b, 238) states that "[i]ntensification concerns the extent of deviation from the unmarked.' If there is a 'normal', unmarked manner of speaking, stottern 
'stutter' denotes a divergence from this manner of speaking with regard to the flow of words. Degree gradation has the effect of further indication of the deviation of the behavior of the subject referent from the normal manner of carrying out the respective action.

(6) a. Der funge stottert sehr.

the boy stutters very

'The boy stutters very much.'

b. Der funge lispelt sehr.

the boy lisps very

'The boy lisps very much.'

The same examples can be found in Russian (7) and French (8), too. The Russian imperfective verb zaikat'sja 'stutter' has a habitual interpretation in (7) and if graded by očen' it expresses that Fëdor is not only stuttering but does so to a high degree. The interpretation for the French example is the same.

Fëdor očen' zaikal-sja $\quad v \quad$ detstv-e.

Fëdor very stuttered-REFL PREP childhood-LOC

'Fëdor stuttered very much in his childhood.'

(8) Le pauvre garçon bégaye beaucoup.

the poor boy stutters a lot

'The poor boy stutters a lot.'

As stated above, the verbs compare the actual manner of behavior with an unmarked manner and thereby indicate a divergence between the actual and the unmarked behavior. Hence, both classes of verbs discussed in this section indicate some divergence between two degrees - which are either the degree of two different objects or of an object and some norm - and do not denote a change of state.

Degree gradation of these two classes of verbs neither interacts with lexical nor grammatical aspect. Stative verbs of comparison do not display aspectual contrasts and degree gradation does not render the predication telic (9). If the time-span adverbial is acceptable, it forces a change of state reading, meaning that in ten minutes the books begin to equal each other. In this shifted reading, ähneln denotes the attained result state and sehr specifies the degree of the resulting state. 
(9) \#Die beiden Bücher ähneln sich in zehn Minuten sehr. the both books be.similar REFL in ten minutes very 'The two books are very similar in ten minutes.'

At least, the German stative verb of comparison gleichen 'to equal' allows the derivation of a change of state predicate by the prefix an-. Angleichen 'to align' can be graded by sehr and is given the same interpretation as change of state predicates.

Verbs of marked behavior show an aspectual opposition, as illustrated in (10). In the perfect (a) as well as progressive (b) example, sehr indicates the degree of divergence from normal speech. There is no difference in the interpretation of degree gradation for these sentences. There is also no effect on telicity as these verbs stay atelic even if graded by sehr (11).
a. Der Junge hat sehr gestottert.
the boy has very stuttered
'The boy stuttered very much.'
b. Der Junge ist sehr am Stottern.
the boy is very at.the stuttering
'The boy is stuttering very much.'
(11) \#Der Junge hat in zehn Minuten sehr gestottert.
the boy has in ten minutes very stuttered
'The boy stuttered very much in ten minutes.'

\subsubsection{Erratic verbs}

Ropertz (2001) uses the term 'erratische Verben' (erratic verbs) for verbs which express a divergence between the actual result and the intended result of an activity. In German, erratic verbs are derived from simplex verbs by the prefix ver-and the reflexive pronoun sich. ${ }^{1}$ Examples are sich verschreiben 'miswrite' derived from schreiben 'write,' sich verlaufen 'get lost' derived from laufen 'go, run' or sich verfahren 'to lose one's way' derived from fahren 'drive.' The derived verbs are marked by a reflexive pronoun, in contrast to their base verbs. Degree gradation (12) specifies the diver-

The prefix ver-is multifunctional and does not always derive a complex verb with erratic meaning from some base verb e.g. verbrauchen 'consume' derived from brauchen 'need'. 
gence between the intended result and the actual result. In (12a), it is not only expressed that the boy got lost and missed his goal but that he missed the goal a lot, so the difference between his intended goal and the place where he actually arrives is large.
a. Der funge hat sich sehr verlaufen. the boy has REFL very got.lost 'The boy got totally lost.'
b. Das Mädchen hat sich sehr verschrieben. the girl has REFL very miswrote 'The girl totally miswrote.'

The relevant gradation scale is one that measures divergence between the intended and the actual result. The scale introduced by the derivational prefix measures some divergence or difference on a scale. Both (12a) and (b) are related to the same kind of scale, as the scale is neither particularly related to going/running in (a) or writing in (b). The link between the gradation scale and the eventuality argument is shown in (13). DIFFERENCE measures the difference between the intended result of the eventuality and its actual result. Stiebels $(1996,151)$ discusses whether intentionality is really a relevant component in the semantic analysis of these verbs. I will not discuss this topic further but make use of the notion of 'intended result' in (13).

$$
\lambda \text { v.high(DIFFERENCE(INTENDED-RESUlt(v), ACTUAL-RESUlt(v))) }
$$

In (12a), the base verb laufen is a manner of motion verb and is a plain activity predicate. The verb does not lexicalize a path scale (cf. the discussion in chapter 3.3 on result verbs) but seems to be associated with a velocity scale, as examples like (14) suggest.

$$
\begin{aligned}
& \text { Er musste sehr laufen um den Bus zu bekommen. } \\
& \text { he had very ran to the bus to get } \\
& \text { 'He had to run very fast in order to catch the bus.' }
\end{aligned}
$$

Some manner of motion verbs, such as laufen or rennen 'run,' admit degree gradation. In this case, the intensifier specifies the velocity of movement. But if prefixed by ver-, the velocity scale is not available anymore for de- 
gree gradation. Examples like (12a) and (14) indicate again that certain constructions can introduce a new scale and block the access to either a lexicalized or conceptually retrieved scale (cf. the discussion in chapter 7.2).

Erratic verbs can be used in the progressive aspect, but degree gradation of this construction is only marginally acceptable (15). If one accepts examples like (15), the intensifier specifies the divergence between the intended and the attained result state, like in the case of the perfect sentence in (12a). There is also a prospective reading of the progressive sentence in (15), meaning that if the boy continues his movement, there will be a large divergence between his received and his intended position. This does not entail that there actually is such a divergence but that his movement will lead to one. The prospective reading is not dependent on the degree context but also results for ungraded erratic verbs in the progressive aspect. Note that in difference to the German sentence, the Enlish translation of (15) is totally acceptable.

??Der funge ist sich sehr am Verlaufen. the boy is REFL very at.the got.lost 'The boy is getting totally lost.'

Neither ungraded nor graded erratic verbs seem to be telic, as the examples in (16) indicate. With regard to aktionsart, erratic verbs behave like degree achievements as they express the attainment of a result state but are atelic. In contrast to degree achievements, degree gradation does not affect telicity of erratic verbs.
a. \#Der Junge hat sich in einer Stunde verlaufen. the boy has REFL in one hour got.lost 'The boy got lost in an hour.'
b. \#Der funge hat sich in einer Stunde sehr verlaufen. the boy has REFL in one hour very got.lost 'The boy got totally lost in an hour.' 


\subsubsection{Gradable action verbs}

Action verbs (the term is taken from Löbner (2012b)) belong to rather different semantic verb classes. I have already discussed verbs of substance emission as well as verbs of sound emission; both classes consist of activity predicates. Both classes of verbs are related to different gradation scales, as discussed above. Further gradable activities belong to the classes of verbs of marked behavior and erratic verbs. But above, I also mentioned that some manner of motion verbs can be graded. This indicates the huge diversity of scales associated with activity predicates. Of particular interest are the verbs of the hit class, like German schlagen 'hit, beat' and treten 'kick.' Löbner (2012b) briefly discusses the German verb schlagen 'hit, beat' and mentions that this verb licenses at least two different readings of verbal degree gradation. He writes: "Intensification may apply to the effort the agent invests into the beating, resulting in a high number of or heavy strokes; it may as well relate to the effect it has on the victim, in terms of pain and harm" (Löbner, 2012b, 238). Taking a sentence like (17) as an example, sehr either specifies the intensity of the beating or the intensity of the effect. That someone puts a great deal of effort into his punch does not entail that the victim is hit hard and that the victim is hit hard does not necessarily entail that a lot of effort was put into the beating. Hence, both readings do not necessarily entail each other.

$$
\begin{aligned}
& \text { Der Boxer hat seinen Gegner sehr geschlagen. } \\
& \text { the boxer has his opponent very hit } \\
& \text { 'The boxer hit his opponent intensively/hard.' }
\end{aligned}
$$

In (18), the attribute chains which link the gradable properties to the eventuality are presented. INTENSITY is either an attribute of the respective action executed in the eventuality and belongs to the manner component of the verb or it is an attribute of the action. Whether INTENSITY is lexicalized in the manner component or inferred from the conceptual knowledge of manners of action is a question that has already been raised in chapter 8. I will leave this question open but assume that the second INTENSITY attribute that belongs to the EFFECT of the action is inferred from the conceptual knowledge of the respective effect. Action verbs which are not related to gradable effects should therefore reject degree gradation. This is clearly true for Levin's (1993) verbs of contact such as German berühren 
'touch, contact' and tasten 'touch' but also for other verb classes like verbs of cutting as schneiden 'cut'.

$$
\begin{array}{ll}
\text { a. } & \lambda \mathrm{v} \cdot(\operatorname{high}(\operatorname{Intensity}(\operatorname{ACtion}(\mathrm{v})))) \\
\mathrm{b} . & \lambda \mathrm{v} \cdot(\operatorname{high}(\operatorname{Intensity}(\operatorname{EFFECt}(\operatorname{ACtion}(\mathrm{v})))))
\end{array}
$$

Löbner mentions that sehr schlagen could also mean to make many strokes. This interpretation arises due to the fact that it is a semelfactive predicate and the same effect as observed for semelfactive verbs of light and sound emission arises. The extent reading is merely an implicature as discussed in the chapters 7.3 and 7.4. There is also a reading of schlagen meaning 'to defeat someone.' In this reading, the verb is not gradable by sehr.

Grammatical aspect does not interact with degree gradation of schlagen. For the graded progressive sentence in (19), the same interpretation obtains as for the graded perfect sentence in (17).

$$
\begin{aligned}
& \text { Der Boxer ist seinen Gegner sehr am Schlagen. } \\
& \text { the boxer is his enemy very at.the beat } \\
& \text { 'The boxer is beating his enemy intensively/hard.' }
\end{aligned}
$$

Since schlagen is an activity, it is atelic. It also remains atelic if graded by sehr. The time-span adverbial does not license the relevant egressive interpretation in (20).

(20) \#Der Boxer hat seinen Gegner in zehn Minuten sehr geschlagen. the boxer has his enemy in ten minutes very beat 'The boxer hit his enemy intensely/hard in ten minutes.'

\subsubsection{Similarities in the compositional patterns}

The discussion above focuses on three essential parameters, namely: (i) the type of scale, (ii) interaction of degree gradation with grammatical aspect and (iii) interaction of degree gradation with telicity. It emerged that four types of scales are of crucial relevance: intensity scales, property scales, divergence scales and quantity scales. Based on the three parameters, the following classification of different types of verbal degree gradation can be derived: 
(i) Degree gradation on an intensity scale: This pattern can be found with verbs of smell/sound/light emission, experiencer verbs as well as gradable activity predicates. Gradation is related to an intensity scale on which a non-differential degree is indicated. Neither lexical nor grammatical aspect is affected by degree gradation.

(ii) Degree gradation on a quantity scale: This pattern is found with verbs of substance emission. Gradation is related to a quantity scale on which a non-differential degree is indicated. Degree gradation interacts with grammatical aspect but not with lexical aspect.

(iii) Degree gradation on a divergence scale: This pattern is found with verbs of comparison, verbs of marked behavior and erratic verbs. Gradation is related to a scale measuring a divergence from some norm or comparison degree. The intensifier indicates a differential degree but does not interact with grammatical or lexical aspect.

(iv) Degree gradation on a property scale: This pattern is found with change of state verbs. Gradation is related to a property scale on which a scalar change is measured. The intensifier indicates a differential degree and interacts with grammatical as well as lexical aspect.

The aim of the classification is not to argue for a uniform compositional pattern for each of these classes. Instead of having a compositional rule for the classes listed above, each semantic verb class requires its own rule of composition for verbal degree gradation. Degree gradation of verbs of smell emission and hit verbs, which both belong to the first class, can be described by a single compositional rule. This is what Löbner (2012b) calls 'subcompositionality' and to which I turn in the next section.

Before I end this section, a short note on the contrast between divergence and property scales on the one hand and intensity and quantity scales on the other hand is required. In the first case, degree gradation leads to the specification of a differential degree, whereas in the second case it is a nondifferential degree specified by sehr. Divergence and quantity scales seem to be always overtly encoded, meaning they are either lexicalized in the verb, as in the case of change of state verbs and verbs of comparison, or 
they are introduced by a morphological construction like the prefix ver-in the case of erratic verbs or the resultative prefix in case of strong resultative constructions. Such scales never seem to be retrieved from conceptual knowledge. This contrast between differential and non-differential degree gradation requires further analysis; in particular a larger cross-linguistic comparison would be interesting.

\subsection{Subcompositionality of verbal degree gradation}

The last subsections summarized different degree gradational patterns identified in the foregoing chapters and identified further ones. The aim of this subsection is to demonstrate that the different patterns are really distinct and that verbal degree gradation cannot be reduced to a single semantic rule of composition. This leads to a problem with the principle of compositionality, which makes up the foundation of semantics. A general formulation of the principle is shown in (21) and taken from Löbner (2012b, 220); one finds very similar formulations in all works concerned with the notion of 'compositionality' e.g. Partee (1984); Partee et al. (1990).

(21) Principle of compositionality: The meaning of a complex expression is a function of the meanings of its components and the syntactic structure of the whole.

I follow Löbner's exposition of the principle of compositionality. He states that the principle presupposes that the semantic operations employed in composition follow rules which he formulates as the assumption of 'regularity of semantic composition' (22).

(22) Regularity of semantic composition: The meaning of a syntactically regular expression derives from the meaning of its components in a regular way.

(Löbner, 2012b, 220)

Regularity of semantic composition means that (i) syntactic expressions are formed by rules and (ii) there are rules which derive the meaning of regularly formed complex expressions from their components. Hence, the rules 
apply generally which means they apply to types of expressions and not to individual expressions. As Löbner states: "Types of expressions subsume different individual cases, and they represent general categories" (Löbner, 2012 b 221), therefore regularity of semantic composition means that "[f] or all complex expressions of a given type, the same semantic operation yields its meaning out of the meaning of their components" (Löbner, 2012b, 221). All that means is that if two individual complex expressions E1 and E2 are of the same type $\gamma$, then the same semantic rule derives the meaning of these complex expressions from the meaning of their components. By 'type' Löbner means syntactically as well as semantically defined types in the sense of Carpenter (1992). For illustration he uses the German verb bluten which belongs to, at least, the following types: 'lexical expression,' 'predicate term,' '1-place predicate term,' '1-place verb,' 'gradable 1-place verb,' 'verb of emission,' 'bluten' (cf. Löbner 2012b, 222). The types are ordered regarding specificity, the first-mentioned types are less specific than those mentioned subsequently. The most specific type is that of the minimal type 'bluten,' which is a subtype of 'verb of emission' and so on.

The resulting question is which types are relevant for semantic composition. Löbner states that two type systems are of importance for compositionality, which are defined by morphosyntactic rules on the one hand and by semantic rules on the other hand. The definition of 'morphosyntactic type' is given in (23) and an example of such a type is 'verb' since verbal inflectional rules have verbs as their (maximal) range of application.

(23) Morphosyntactic types: $t$ is a morphosyntactic type iff there is a morphosyntactic rule that has $t$ as its (maximum) range of application. (Löbner, 2012b, 222)

Löbner (2012b, 222) defines semantic types as presented in (24). Usually, '1-place predicate term' is taken to be a semantic type since such terms provide a uniform domain of application for a rule of argument saturation. ${ }^{2}$

(24) Semantic types: $t$ is a semantic type iff there is a semantic composition rule that has $t$ as its (maximum) range of application.

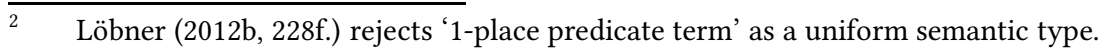


It is a question whether semantic and syntactic types coincide such that there is a direct corresponding syntactic type for each semantic type. In the classical scheme (model-theoretic semantics), as Löbner calls it, it is assumed that both systems match (cf. Montague 1970, 1973 among others). This is expressed by the postulate of 'homomorphy of syntactic and semantic composition' in (25).

Homomorphy of syntactic and semantic composition: For every complex expression of a particular syntactic composition, the same rule of semantic composition applies. (Löbner, 2012b, 225)

What this means is that the way complex expressions are syntactically formed determines their semantic composition. For example, there may be a general rule for the syntactic combination of a verb and its subject argument and it is assumed that there is a single semantic rule corresponding to the syntactic one. But a look at examples such as those in (26) reveals that there is no uniformity regarding the subject arguments of particular verbs. We have a personal name in (a), a definite noun phrase consisting of the definite article and a common noun in (b) and a quantified NP consisting of a quantifier and a common noun in (c).
a. John is sleeping.
b. The child is sleeping.
c. All the children are sleeping.

For all three cases, we have the same rule of syntactic composition, although the three different subject arguments are of different logical types. Such a mismatch between the logical types of subject arguments led to a generalization to the worst case and gave rise to Generalized Quantifier Theory (Barwise \& Cooper 1981) which takes all subject arguments to be generalized quantifiers. A mismatch between syntactic and semantic composition is avoided by postulating a common type for all noun phrases, irrespective whether they are plain personal names, determined nouns or quantified nouns. This preserves the homomorphism between syntactic and semantic composition.

Löbner argues that there are clear cases of a genuine mismatch between syntactic and semantic composition for which he coins the term 'subcompositionality.' His definition of subcompositionality is presented in (27) 
and what is meant is that for a certain regular syntactic construction not a single rule of semantic composition but different rules are required. Subcompositionality contradicts the assumption that semantic composition is regular (22) - which underlies the principle of compositionality. Hence, subcompositionality provides an attack on the paradigm of formal semantics which builds on the notion of compositionality.

[A] syntactic construction is subcompositional if there is no uniform rule of semantic composition for it.

(Löbner, 2012b, 224)

Löbner's primary example of 'subcompositionality' is verbal degree gradation. The examples in (28) can be used for illustration. All the sentences are basically of the same construction type, which is 'sehr + intransitive verb.' As was shown in detail in the chapters 6 to 8, change of state verbs, experiencer verbs and verbs of substance emission differ regarding verbal degree gradation and the different semantic patterns that can be observed are not reducible to a single, uniform pattern. Since we get a different pattern of verbal degree gradation for these examples, we need to postulate a different semantic rule of composition for each. Hence, we have the same syntactic construction but different semantic rules for its interpretation.
a. Das Kind ist sehr gewachsen.
the child is very grown
'The child has grown a lot.'
b. Sein Kopf schmerzt sehr.
his head hurts very
'His head hurts very much.'
c. Die Wunde blutet sehr.
the wound bleeds very
'The wound is bleeding a lot.'

Löbner (2012b, 239) states: "Although the resulting picture of semantic composition is diverse and complex, there appear to be sub-rules that apply homogeneously for each type of gradable verb." The reasons for the subcompositionality of verbal degree gradation are (i) the verbs are related to different scales and (ii) the scales are differently anchored in the verb meanings. In (28a), the scale measures the change in a property of the ref- 
erent of the theme argument; in (b), it is the intensity of the feeling and in (c) it is the quantity of the emitted blood. Also wachsen 'grow' is lexically scalar, as discussed in the last section, whereas in (b) and (c) the gradable property is an attribute of an implicit argument of the verb. But in both cases, it is a different kind of implicit argument.

The different compositional patterns correspond to different logical equivalences as Löbner (2012b, 238) mentions. This is illustrated by the paraphrases of verbal degree gradation for verbs of different semantic classes in (29). The paraphrases in (29a) to (d) illustrate the main patterns discussed in chapters 6 to 8 for change of state verbs (a), verbs of smell emission (b), verbs of substance emission (c) and experiencer verbs (d). The paraphrases in (d) for verbs of comparison, (e) for verbs of marked behavior and (f) for erratic verbs are taken from Löbner (2012b, 239).
a. sehr wachsen $\leftrightarrow$ viel größer werden very grow 'get much taller'
b. $\quad$ sehr riechen $\leftrightarrow$ starken Geruch absondern very smell 'emit strong smell'
c. $\quad$ sehr bluten $\leftrightarrow$ viel Blut absondern very bleed 'emit much blood'
d. $\quad$ sehr lieben $\leftrightarrow$ starke Liebe empfinden very love 'feel strong love'
e. sehr ähneln $\leftrightarrow$ sehr ähnlich sein very be.similar 'be very similar'
f. $\quad$ sehr stottern $\leftrightarrow$ sehr stockend sprechen very stutter 'speak very haltingly'
g. $\quad$ sehr sich verlaufen $\leftrightarrow$ sehr falsch laufen very be.lost 'go completely the wrong way'
h. $\quad$ sehr schlagen $\leftrightarrow$ stark schlagen very hit 'hit hard'

The reason for the different paraphrases in (29) is the fact that the attribute representing the gradable property differs from verb class to verb class. This can best be illustrated by using attribute chains connecting the gradable property to the eventuality. (30) shows the attribute chains for graded verbs of smell/sound/light emission in (a) and for graded action verbs in (b). 


$$
\begin{array}{ll}
\text { a. } & \lambda \mathrm{v}(\mathrm{high}(\operatorname{Intensity}(\operatorname{Emittee}(\mathrm{v})))) \\
\text { b. } & \lambda \mathrm{e}(\operatorname{high}(\operatorname{Intensity}(\operatorname{EFFECt}(\operatorname{ACtion}(\mathrm{e})))))
\end{array}
$$

The common core of the two cases in (30) is that sehr applies to an INTENSITY attribute but the attribute is related via different functions to the eventuality. In (a) INTENSITY is an attribute of EMITTEE which is the implicit semantic argument of the verb, whereas in (b) it is an attribute of the EFFECT of the ACTION. One could abstract over these functions by saying that we need an appropriate function $\mathrm{F}$ which relates INTENSITY to the eventuality (31). But $\mathrm{F}$ is dependent on the semantic class of verbs and cannot be generalized. This means that there is no general rule that allows us to infer the function that relates the gradable property to the eventuality.

$$
\lambda \mathrm{v} \lambda_{\mathrm{F}}(\operatorname{high}(\operatorname{Intensity}(\mathrm{F}(\mathrm{v}))))
$$

Löbner $(2012 b, 239)$ basically argues that the fact that the different equivalences cannot be unified in a single pattern, provides evidence for the subcompositionality of verbal degree gradation. This is even more revealing if we do not only compare verbs which are related to degree gradation on an intensity scale. Examples of degree gradation on a divergence scale have been presented above and it seems that indicating a differential degree cannot be reduced to the indication of a non-differential degree and vice versa. This further supports the irreducibility of the different subcompositional patterns to a single one.

As argued in section 5.4, what distinguishes adjectival degree gradation from verbal degree gradation is that the former is not subcompositional. The semantic composition of sehr plus adjective can be accounted for by a single rule. After illustrating subcompositionality in more detail, I finally turn to the interaction of verbal degree gradation with grammatical aspect and also telicity in the next section.

\subsection{Event-dependent degree gradation}

The discussion of different semantic verb classes revealed that degree gradation interacts with grammatical aspect only in case of (atelic) change of state verbs and verbs of substance emission. In Fleischhauer (2013), I coined the term 'event-dependent degree gradation' for cases in which 
grammatical aspect affects degree gradation, whereas those cases in which it does not, I called 'event-independent degree gradation.' For change of state verbs and verbs of substance emission, it seems obvious that there is a relationship between the progression of the event and the degree on the associated scale. Starting with change of state verbs, the verb verbreitern 'broaden, widen' in example (32) can be taken for illustration. As long as the event of widening takes place, the width of the crack has to increase. If the width of the crack is not increasing anymore, it cannot truthfully be said that the crack is still widening. What definitely is excluded is that the event is progressing and either no change in width obtains or that the width is even decreasing. That changes happen continuously is not a necessary condition, a change could also occur in a single sudden jump from the initial to the final degree. But such a case would exclude the application of the progressive aspect, as it would happen instantaneously. In the remainder, I am only concerned with durative changes that do not happen instantaneously.

$$
\begin{aligned}
& \text { Der Riss verbreitert sich. } \\
& \text { the crack widens REFL } \\
& \text { 'The crack is widening.' }
\end{aligned}
$$

Continuity of the change does not entail that the change obtains at each single moment of the event. This is definitely the case for a sentence like The girl has grown a lot in two years. The time-adverbial picks out a temporal interval of two years and it is not to be the case that at each single moment the girl increased in size. We have different granularities of relevant instances in which the respective change needs to obtain to speak of a single event of changing. We easily arrive at a discussion of event identity and the question when do we speak of a single event and when do we have to speak of two or more events of the same type. I will not go into the details of that discussion, but what is most relevant for the current discussion is not the exact granularity of the change but that it can be described as being a monotonic increase on the respective scale.

For verbs of substance emission, a similar picture obtains. Bluten normally denotes a continuous emission of blood. As in the case of change of state predications, the longer the event of bleeding proceeds, the more blood is emitted. Since bleed describes a continuous emission 
of blood, the quantity of emitted blood increases as the event unfolds. There is a monotonic increase of the degrees on the quantity scale. In the case of event-dependent degree gradation, a relationship between the event and the degree on the respective scale holds, this can be informally summarized as in (33). It states that there is a dependency of the degree on the scale and the event such that the progression of the event leads to increasing degrees. ${ }^{3}$

(33) The more the event progresses, the more the degree on the scale increases.

The constraint in (33) does not hold for verbs such as dröhnen 'drone' or ängstigen 'frighten.' If an engine is droning, the intensity of the emitted sound does not (necessarily) increase - or decrease - if the event progresses. Surely, it may be the case that the intensity increases/decreases but this is merely incidental, whereas it is necessarily the case that the quantity of emitted blood increases as the bleeding event unfolds. This does not entail that bluten is a lexically scalar verb, as I only claim that the constraint holds if the quantity scale is activated. In other words: if the scale is activated, the constraint must hold.

(a)

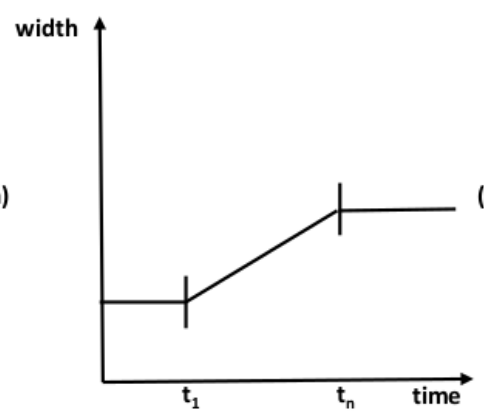

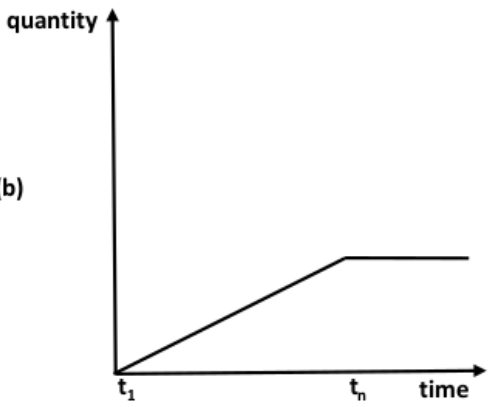

Figure 13: Graphical representation of the relationship between unfolding events (temporal progression) and increasing degrees.

To be accurate, the constraint also holds for verbs expressing a decrease of degrees as in The temperature is falling. 
Figure 13 is a graphical representation of the relationship between the progression of the event and the increase on the respective scale. In (a), we have the case of a change of state verb like widen. The referent of the theme argument has an initial degree of width and during the event, the width increases. $t_{1}$ and $t_{n}$ indicate the initial moment and the final moment of the widening event respectively. In (b), the increase of the quantity of emitted substance is shown for verbs like rain or bleed. There is an idealization in figure 13, as the change and the emission are represented as constant before and after the respective event. This need not to be the case and is only done for the sake of illustration.

The constraint in (33) requires a homomorphic mapping between the event and the scale which guarantees that the degree increases of the event progresses. Such a kind of homomorphism has been proposed by Krifka (1986, 1998) for explicating the notion of 'incremental change.' Based on Krifka's and related work (e.g., Caudal \& Nicolas 2005; Kardos 2012), a homomorphic mapping between the part structure of events and the degrees of an associated scale can be defined as in (34) and (35). The formulas in (34) and (35) presuppose structured domains of events and degrees. Events can be decomposed into subevents and the subevents can be brought into a temporal order (see Krifka 1998, 206 on the temporal trace function that maps events onto their running time). Degrees are inherently linearly ordered. (34) ensures that if a function $f$ maps an event onto a scale and returns some degree $d$, then for each subevent $e$ ' of $e$, there is a degree $d$ ' which is smaller than $d$ and is returned for mapping $e^{\prime}$ onto the scale. ${ }^{4}$ It is not assumed that $f$ directly maps the eventuality and a scale but rather that it relates the eventuality and the scale via some attribute chain as discussed above.

$$
\begin{aligned}
& \text { Mapping to degrees: } \forall \mathrm{e} \forall \mathrm{e}^{\prime} \forall \mathrm{d}\left[\mathrm{f}(\mathrm{e})=\mathrm{d} \wedge \mathrm{e}^{\prime} \subset \mathrm{e} \rightarrow \exists \mathrm{d}^{\prime}\left[\mathrm{d}^{\prime}<\mathrm{d} \wedge\right.\right. \\
& \left.\left.\mathrm{f}\left(\mathrm{e}^{\prime}\right)=\mathrm{d}^{\prime}\right]\right]
\end{aligned}
$$

In (35), it is expressed that if a function $f$ maps an event $e$ onto a scale and returns a degree $d$ and if there is some $d$ ' smaller than $d$, there exists some subevent $e^{\prime}$ for which $d^{\prime}$ is the value of the function.

See Krifka (1998) for a formal explication of event mereology. Subevents, i.e., parts of events, are ordered with respect to temporal precedence. 


$$
\begin{aligned}
& \text { Mapping to subevents: } \forall \mathrm{e} \forall \mathrm{d}^{\prime} \forall \mathrm{d}^{\prime}\left[\mathrm{f}(\mathrm{e})=\mathrm{d} \wedge \mathrm{d}^{\prime} \leq \mathrm{d} \rightarrow \exists \mathrm{e}^{\prime}\left[\mathrm{e}^{\prime} \subset \mathrm{e} \wedge\right.\right. \\
& \left.\left.\mathrm{f}\left(\mathrm{e}^{\prime}\right)=\mathrm{d}^{\prime}\right]\right]
\end{aligned}
$$

The two conditions in (34) and (35) do not hold in case of non-incremental changes. Take stink as an example. There is a function that relates the eventuality to an intensity scale and returns (in the case of degree gradation) an intensity degree. The function can return the same degree of any subeventuality.

There are two further conditions which ensure uniqueness of degrees (36) and events (37). (36) states that each subevent $e$ ' is mapped onto a unique $d^{\prime}$, whereas (37) expresses that each degree is mapped onto a unique subevent.

(36) Uniqueness of degrees: $\forall \mathrm{e} \forall \mathrm{e}^{\prime} \forall \mathrm{d}\left[\mathrm{f}(\mathrm{e})=\mathrm{d} \wedge \mathrm{e}^{\prime} \subset \mathrm{e} \rightarrow \exists\right.$ ! $\mathrm{d}^{\prime}\left[\mathrm{d}^{\prime} \leq \mathrm{d} \wedge\right.$ $\left.\left.\mathrm{f}\left(\mathrm{e}^{\prime}\right)=\mathrm{d}^{\prime}\right]\right]$

(37) Uniqueness of events: $\forall \mathrm{e} \forall \mathrm{d} \forall \mathrm{d}^{\prime}\left[\mathrm{f}(\mathrm{e})=\mathrm{d} \wedge \mathrm{d}^{\prime} \leq \mathrm{d} \rightarrow \exists \mathrm{e}^{\prime}\left[\mathrm{e}^{\prime} \subseteq \mathrm{e} \wedge\right.\right.$ $\left.\left.\mathrm{f}\left(\mathrm{e}^{\prime}\right)=\mathrm{d}^{\prime}\right]\right]$

The conditions defined in (34) to (37) guarantee that there is a unique degree associated with each subevent and that each subevent is associated with a unique degree. Mapping to degrees and mapping to subevents defines the notion of an 'incremental (scalar) change.' By adding the uniqueness conditions in (36) and (37) the stricter notion of 'strictly incremental (scalar) changes' results. For the following analysis, it is not crucial whether one assumes the stronger or just the weaker notion of incrementality; all that is required is incrementality.

Following Filip's (1999; 2005) analysis of grammatical aspect, perfective aspect restricts the denotation of verbs to total events, whereas imperfective aspect restricts it to partial events. Total events do not make reference to their various phases but are taken as a single and atomic whole (for a formal definition of the totality inducing perfective operator see Filip 2005, 133f.). Progressive aspect, as a subtype of the general imperfective, restricts the denotation of the event to a subevent (for a semantic definition of progressive aspect see chapter 6.5.1). We derive the difference between the two interpretations in (38a) and (b) due to restricting the denotation of the verb to the total event in (a) but to a subevent in (b). In (a), sehr indicates the total amount of change as it provides a specifation of the difference 
obtained in the total event. In (b), sehr indicates the amount of change at a certain stage of the event since the denotation is restricted to a subevent.
a. Der Riss hat sich sehr verbreitert. the crack has REFL very widened 'The crack widened a lot.'
b. Der Riss war sich sehr am Verbreitern. the crack was REFL very at.the widening 'The crack was widening a lot.'

In (a) as well as (b), sehr only indicates the difference between the degree at the beginning of the total, respectively the subevent, and the degree at the end of the total, respectively the subevent. Since grammatical aspect has scope over degree gradation (cf. the discussion in chapter 4) first sehr applies to the verb and specifies the resulting change. After that the aspectual operator applies to the construction of 'sehr + verb' and restricts the denotation the verb.

The same analysis can be applied to examples like (39). In (a), sehr specifies the total quantity of blood emitted in the event, whereas in (b) it is the quantity of blood emitted at a certain stage of the event. These different readings result from restricting the denotation of the verb to total events in (a) but to a proper part of the bleeding event in (b).
a. Die Wunde hat sehr geblutet. the wound has very bled 'The wound bled a lot.'
b. Die Wunde war sehr am Bluten. the wound was very at.the bleeding 'The wound was bleeding a lot.'

The next question is why degree gradation affects telicity of change of state verbs but not of verbs of substance emission or other classes of gradable verbs. In chapter 6, I presented Hay et al.'s (1999) analysis of degree achievements. According to their view, telicity arises by inducing a lower bound on the change. Such a lower bound can either be a natural endpoint, a telos indicated by the verb, or introduced by a monotone-increasing intensifier such as English slightly or German sehr. Specifying a lower bound for the incremental change results in a telic predication. Degree gradation 
can only affect telicity if the verb expresses an incremental change along a scale. This is not the case with verbs of smell/light/sound emission and experiencer verbs, therefore gradation cannot lead to a telic predication in these cases. But if the proposal presented above is right, verbs of substance emission also express an incremental change (see Harley 2005 for a similar view). The question is: why does degree gradation not affect telicity of these verbs? In contrast to change of state verbs, verbs of substance emission do not just express a change in a property of the referent of the theme argument but it is the quantity of the referent of the theme argument that is affected. The same holds for incremental theme verbs like eat, drink or read (the term 'incremental theme' goes back to Dowty 1991). What is special about incremental theme verbs is that the telicity of the predication is dependent on the referential properties of the theme argument. This is usually captured by the notion of 'aspectual composition' (40).

(40) Aspectual composition of incremental theme predications:

An incremental theme verb combined with a quantized incremental theme argument yields a telic predication, whereas if it combines with a cumulative incremental theme argument it yields an atelic predication (e.g., Krifka 1986, 1998; Filip 1999, 2000).

The notions of quantization and cumulativity are defined in (41) and (42) respectively. Singular count nouns like apple have quantized reference, whereas mass nouns and bare plurals refer cumulatively. Quantization is tantamount to saying that no proper part of, for example an apple, falls under the predicate apple again, and cumulativity means that you can add apples to apples and denote the sum by the predicate apples again. This property does not hold for quantized predicates as you cannot denote the sum of two individual apples by the predicate apple; rather you have to use the plural apples. Similarly, the property of quantization does not hold for bare plurals and mass nouns as a proper part of apples or soup can be apples or soup again.

(41) Quantization: A predicate $P$ is quantized iff $\forall \mathrm{x}, \mathrm{y}[\mathrm{P}(\mathrm{x}) \wedge \mathrm{P}(\mathrm{y}) \rightarrow \neg(\mathrm{y}<\mathrm{x})]$

(A predicate $P$ is quantized iff it applies to two individuals $x$ and $y$, and none of them is a proper part of the other.) 
Cumulativity: A predicate $P$ is cumulative iff $\forall \mathrm{x}, \mathrm{y}[\mathrm{P}(\mathrm{x}) \wedge \mathrm{P}(\mathrm{y}) \rightarrow \mathrm{P}(\mathrm{x} \oplus \mathrm{y})]$

(A predicate $P$ is cumulative iff it applies to two individuals $x$ and $y$, then it also applies to the sum of both.)

If eat combines with a quantized incremental theme argument as in (43a), the predication is telic. If the incremental theme argument has cumulative reference (b), the predication is atelic. The event-degrees homomorphism also accounts for incremental theme verbs as these verbs describe a change along a quantity scale. Quantization involves specifying the quantity of the incremental theme argument and thereby inducing a lower bound on the existential change (see Czardybon \& Fleischhauer 2014 and the literature cited therein for different strategies of realizing telic incremental theme predications).
a. Peter hat den Apfel in zehn Minuten gegessen.
Peter has the apple in ten minutes eaten
'Peter ate the apple in ten minutes.'
b. \#Peter hat Äpfel in zehn Minuten gegessen.
Peter has apples in ten minutes eaten
'Peter ate apples in ten minutes.'

An incremental theme argument is more and more affected as the event progresses. In this regard, the implicit emittee argument of verbs of substance emission can be considered to be an incremental theme argument since the degree of its affectedness increases as the event unfolds. The implicit incremental theme argument of verbs of substance emission denotes the substance emitted during the event and such substances are usually mass terms. As mass nouns refer cumulatively, the predication is atelic (the same argumentation is given by Harley 2005, 47f.). This presupposes a homomorphic mapping between the event and the scale measuring the quantity of emitted substance.

If the emittee argument is an implicit incremental theme argument, quantization of the argument should result in a telic predication. The addition of adnominal quantity expressions like much and a lot leads to quantization of inherently cumulative nouns. This is shown in (44). The bare mass noun wine is not able to delimit the event in (44a) but by adding a lot, 
a telic sentence results (for similar examples see Bach 1986). A lot quantizes the incremental theme argument, as it is not (necessarily) the case that a proper part of 'a lot of wine' can be denoted by a lot of wine again. The lower bound induced by $a$ lot in (44b) is a contextually dependent large quantity of wine.

a. \#I drank wine in ten minutes.

b. I drank a lot of wine in ten minutes.

Grading a verb of substance emission like eitern 'fester' by the addition of sehr does not result in telicity (45); also, sehr specifies the quantity of emitted stuff. But this is different if we paraphrase the verb eitern either by Eiter verlieren 'lose pus' or Eiter abgeben 'emit pus' like in (46). In the paraphrase, the emittee is not any more implicit but it is the direct object of the verb and sehr is replaced by the adnominal quantity expression viel. The sentence is telic, irrespective whether the verb verlieren 'lose' or abgeben 'emit' is used.

\#Die Wunde hat in zehn Minuten sehr geeitert.

the wound has in ten minutes very festered 'The wound festered a lot in ten minutes.'

(46) Die Wunde hat in zehn Minuten viel Eiter verloren/abgegeben. the wound has in ten minutes much pus lost/emited 'The wound emited a lot of pus in ten minutes.'

The contrast between (45) and (46) allows for, at least, two different explanations. Either sehr is not able to quantize an (implicit) nominal argument by specifying its quantity or an implicit semantic argument is not able to measure out an event. The second option is in accordance with Tenny's (1992; 1994) claim that only direct internal arguments can measure out, whereas Harley (2005) claims that implicit, i.e., incorporated arguments can do, too. The example in (47) supports Harley's view as the addition of the measure phrase zehn Liter 'ten liters' results in a telic predication due to quantization of the implicit incremental theme argument. Hence, the implicit argument can be quantized and quantization leads to a telic predication but it seems that degree expressions and measure phrases function differently with respect to verbs of substance emission. 

Es hat in einer Stunde zehn Liter geregnet.
it has in one hour ten liters rained
'It rained ten liters in an hour.'

A further way of quantizing the implicit incremental theme argument is by using the verbal particle aus- (48). Prefixation derives the verb ausbluten 'bleed out' which can be paraphrased as 'emitting all of the blood' (for a semantic analysis of the German verbal particle aus- see Stiebels 1996; McIntyre 2003).

$$
\begin{aligned}
& \text { Das Schwein war in zehn Minuten ausgeblutet. } \\
& \text { the pig was in ten minutes out.bled } \\
& \text { 'The pig bled out in ten minutes.' }
\end{aligned}
$$

There is ample evidence that the inherent incremental theme argument can get quantized and that its quantization affects the telicity of the predication. This results in the question as to why sehr cannot quantize the inherent incremental theme argument and therefore degree gradation by sehr does not result in a telic predication. As I do not have a conclusive answer to this question, it has to be left open for future research.

\subsection{Conclusion}

This chapter dealt with two general topics. First, it was shown that verbal degree gradation is subcompositional as the different compositional patterns summarized in the first section cannot be unified in a single compositional rule. Second, the interaction between degree gradation and both grammatical aspect and telicity has been discussed. Grammatical aspect affects degree gradation if there is a homomorphic mapping between the event and a scale such that the degree on the scale increases if the event progresses. Such a constraint holds for change of state verbs and verbs of substance emission but not for other classes of gradable verbs. The interaction of telicity with degree gradation is also dependent on this homomorphism as the specification of a lower bound on that scale results in a telic predication. Sehr is able to induce a lower bound in the case of (atelic) change of state verbs but not in the case of verbs of substance emission. As demonstrated in the last section, the reason is not that the implicit incre- 
9 Gradation, aspect, and telicity

mental theme argument cannot be quantized, rather that sehr is not able to quantize the emittee argument. Why this is the case is still an open question and requires further research. 